\title{
Carmen Maíz-Arévalo
}

\section{Expressing disagreement in English as a lingua franca: Whose pragmatic rules?}

Abstract: Multicultural classrooms provide the intercultural pragmatist with a breeding ground to get firsthand information on intercultural communication. In such a context, if English is used as a lingua franca, these classrooms also become an ideal setting to observe the pragmatics of this relatively unknown variety. The present article aims to analyze qualitatively a sample of data produced by a multicultural group of masters students in which English is used as the lingua franca. More specifically, I intend to answer the following research question: In a multicultural class where English is the medium of instruction and students' peer to peer communication, whose pragmatic "rules" are followed? In other words, do these speakers stick to their own cultural pragmatic rules or follow nativelike ones? More specifically, I focus on the speech act of disagreement given its face-threatening nature and its disruptive potential if carried out in what interlocutors might perceive as the "wrong” way. Disagreement was also chosen given the relative paucity of studies on this speech act - as opposed, for example, others like requests or compliments. For this purpose, the 10 students - from very different cultural backgrounds - were asked to carry out a group assignment. Their negotiation and discussion process, however, was computer-mediated via the use of forums rather than face-to-face. This allowed the researcher to collect naturally occurring, spontaneous data in a relatively easy way (without the need for transcription). It also gave the students the opportunity to interact in a more democratic way. In fact, by being an asynchronous discussion online, they did not have to fight for the conversational turn, but all of them had the chance to contribute to the discussion at their own pace. The sample so collected consists of 15,598 words. The limitation of the sample calls for a qualitative rather than a quantitative approach but is valuable insofar as it represents naturally occurring data. Disagreement expressions were classified according to two main categories: strong and mitigated disagreement (following Kreutel 2007; Pomerantz 1984 and Rees-Miller 2000). Inspection of the data reveals that students on the whole show a tendency to avoid strong disagreement whilst favoring mitigated disagreement of different sorts (e.g., use of hedges, asking for clarification, giving explanations, etc.). Moreover, students with high linguistic proficiency displayed a wider range of strategies, following a more nativelike pattern - specifically; they seemed to follow the pragmatic rules of British English. On the other hand, students whose linguistic proficiency was lower also showed a tendency to avoid strong 
disagreement but were much more limited with regard to their mitigating strategies, favoring the nonnative overuse of expressions of regret and hedges. Other variables, such as familiarity with their partners and their linguistic proficiency, as well as the nature of the task at hand, also played a central role in the students' choice of the common rules of a native variety.

Keywords: English as lingua franca, disagreement, collaborative online writing, pragmatic competence

Carmen Maíz-Arévalo: Universidad Complutense. E-mail: cmaizare@filol.ucm.es

\section{Introduction}

Multicultural classrooms where English is used as lingua franca (henceforth ELF) are both a pragmatic minefield and a breeding ground for the study of intercultural pragmatics. In fact, the interlocutors share English as a common language but come from different sociocultural backgrounds where there are "preferred ways of saying things” (Kecskes 2007: 192). Despite some exceptions (House 2002, 2003; Meierkord 2000; Knapp and Meierkord 2002; Seidlhofer 2004, 2005; Hülmbauer, Böhringer, and Seidlhofer 2008), relatively little is still known about ELF. This paper focuses on the speech act of disagreement in a multicultural classroom where English is the common language. More specifically, the paper analyzes how students in this multicultural learning environment expressed disagreement when interacting online throughout the completion of a written group assignment. Collaborative writing was envisaged as the ideal setting to promote negotiation and discussion where disagreement was to be expected (Angouri and Locher 2012). Students had to negotiate their respective analyses before reaching a final consensus. Being an intercultural group, the way disagreement was expressed turned this context into a perfect breeding ground for potential misunderstandings and pragmatic failure.

Keeping this in mind, the present study aims to answer the following research question: In a multicultural class where English is the medium of instruction and students' peer to peer communication, whose pragmatic "rules" are followed? In Kecskes's (2007: 192) words, the key question that needs answering is, "with no native speakers participating in the language game how much will the players stick to the original rules of the game?"

The rest of the paper is structured as follows: Section two offers a definition of the speech act of disagreement and a state of the art of its research. The third 
1 section presents the methodology; more specifically, I describe the setting and participants involved in the research, the procedures used to collect the data and 3 the rationale for choosing these procedures. Section four begins with the presen4 tation of different taxonomies regarding disagreement before analyzing the data 5 and discussing the results. Given the relatively small size of the corpus and the 6 complexity of this speech act, I firmly believed that a qualitative, more finegrained analysis would render more informative results. Finally, section five 3 offers some conclusions and points to future research.

\section{Theoretical background}

13 For the ordinary native speaker of English, disagreeing is simply seen as the 14 opposite of agreement. Disagreement is defined by the online Merriam-Webster 15 dictionary $^{1}$ as "the failure to agree." In other words, agreement is generally per16 ceived as the desirable, preferred option (Pomerantz 1984) while disagreement is 17 regarded as its negative, undesirable counterpart. ${ }^{2}$ However, research has demon18 strated that disagreement is not necessarily the dispreferred option (e.g., Hayashi 19 1996; Kakavá 1993, 2002; Tannen 2002) but can be used even to foster intimacy 20 and sociability (Schiffrin 1984; Tannen and Kakavá 1992). In sum, the speech act 21 of disagreement is much more complicated than it may seem at first sight and 22 cannot be considered as a unified phenomenon but very much dependent on context (Sifianou 2012: 1555; Angouri and Locher 2012: 1549).

However, and despite its complexity, disagreement has been relatively less studied than other speech acts such as requests or compliments (Díaz Pérez 2003; Lawson 2009). In fact, disagreement seems to have attracted attention from researchers only relatively recently. Thus, in spite of the existence of pioneering studies on this topic (Kakavá 1993; Kotthof 1993; Pomerantz 1984; Tannen 1994, among others), it has been in recent times that we have witnessed a proliferation of studies on this speech act. ${ }^{3}$ However, the majority of studies on disagreement have focused on the production of this speech act by native speakers of English 2 (and its different varieties) (Angouri and Marra 2012; Baym 1996; Bolander 2012; Grimshaw 1990; Gruber 2001; Holmes and Marra 2004; Langlotz and Locher 2012; 4 Muntigl and Turnbull 1998; Rees-Miller 2000). English has also been contrasted

$1 \mathrm{http}: / /$ www.merriam-webster.com/ (accessed 20 June 2013).

2 Even the formation of the word itself contributes to this adverse perception, thanks to the use of the negative prefix "-dis."

393 As an example, it is worth pointing out that special issues on disagreement were published by

40 the Journal of Pragmatics in 2002 and 2012. 
with other languages such as Greek (Georgakopoulou 2001; Koutsantoni 2005; Sifianou 1992), Chinese (Bond, Zegarac and Spencer-Oatey 2000; Liang and Han 2 2005), Japanese (Lawson 2009; LoCastro 1986; Nakajima 1997) or Spanish (García 1989; Santamaría-García 2006), to mention some examples.

In comparison, however, and as pointed out by Bardovi-Harlig and Salsbury (2004: 200), "relatively less research on agreements and disagreements has been conducted on the speech of learners and nonnative speakers." ${ }^{4}$ Likewise, Lawson (2009: 4) states that, "given the importance of learning how to express one discord effectively through the medium of the target language, there has, to date, been relative paucity of research into how nonnative speakers of English express disagreement in informal discussion.” Quite significantly, even the reputed Centre for Advanced Research on Language Acquisition (CARLA) ${ }^{5}$ reports having researched the following speech acts: "apologies," "complaints," "compliments/ responses," "refusals," "requests," and "thanks," but the speech act of disagreement has still not been included in their repertoire.

The landscape is not as barren as it may seem, however. In the 1980s, two canonical studies on disagreement by learners of English as a foreign language (EFL henceforth) were conducted; namely, Beebe and Takahashi (1989) and Pearson (1986). As Bardovi-Harlig and Salsbury (2004) point out, Beebe and Takahashi used discourse completion tests (DCT) for their study, and, although shedding valuable information, their results cannot be comparable with naturally occurring conversation. Pearson (1986) compared disagreements produced by EFL Japanese learners with those produced by native speakers of English in naturally occurring conversation. More recently, Kreutel (2007) contrasted the production of learners of EFL with that of native speakers of American English. Collected as DCTs, her data confirm what has often been reported in the literature; namely, non-native speakers' expressions of disagreement lack complexity (see also Bell 1998; Nakajima 1997). In other words, learners employ mitigation strategies such as the use of hedges or the so-called token agreement (Pomerantz 1984) less frequently than native speakers do. They also display a tendency to express disagreement bluntly by means of the negative adverb "no" or the performative "I

\footnotetext{
4 In this respect, it is worth commenting the work by Marra (2012), who studied naturally occurring interactions between native and migrant trainees working in New Zealand during business meetings. She concludes that acquiring this sociopragmatic competence can be quite complex for the nonnative employees. Quite significantly, the reason why this may be so does not only rely on the nonnative speakers themselves but in the fact that the native colleagues "appear not to take up potential disagreements, instead reinterpreting any attempts at disagreement by the skilled migrants as a different speech act" (2012: 1588).

5 Available at http://www.carla.umn.edu/speechacts/descriptions.html
} 
1 disagree." A third option is simply not to express the disagreement at all (Pearson 1986).

3 Other studies on the expression of disagreement by nonnative speakers of 4 English follow a different methodology from the use of DCTs. More specifically, 5 Bardovi-Harlig and Salsbury (2004) carried out a one-year longitudinal study of 6 the disagreements produced by 12 learners of English as a second language (ESL) 7 as they interacted with native speakers during conversational interviews. The 3 longitudinal character of the study reflected progress in the students' acquisition of pragmatic competence. Thus, they report that most learners started the study 0 with direct disagreements but ended up elaborating their disagreements as time 11 passed. Lawson (2009) follows a similar methodology and records interviews 12 between 30 Japanese speakers of English and 30 native speakers of American 13 English discussing on polemic issues. Although some of his findings replicate 14 prior studies (e.g., the use of more blunt expressions of disagreement in the case 15 of nonnative speakers such as, "I don’t think so"), he also reports remarkable 16 facts such as the frequent use of the performative "I disagree" among native 17 speakers, as opposed to previous research. As already mentioned, this reflects 18 that naive generalizations on such a complex speech act should be carefully 19 avoided.

20 Hence, the aim of this paper is to contribute to modestly redress the balance 21 in support of disagreements as produced by non-native speakers of English. Sec22 ondly, this paper also seeks to address disagreement in a collaborative ${ }^{6}$ context 23 where no power differences can be observed. As pointed out by Lawson (2009: 24 11), "there appears to be an absence of studies which examine the common, yet 25 highly complex speech act of offering an opinion in everyday conversation with a 26 dialogue partner of relatively equal status or power.” Disagreement is also tackled 27 from the position of computer-mediated communication. Previous studies (Lan28 glotz and Locher 2012) have dealt with online disagreement but in a conflictive 29 context rather than a cooperative one. Finally, a further contrast with previous 30 studies is that all the participants are non-native speakers and use English as a 31 lingua franca rather than being L2 learners proper. The question that this raises is 32 what pragmatic expectations this community of practice has. In other words, 33 since all the participants come from different cultural backgrounds and have 34.

35

6 Kempf (2003) distinguishes a four-step escalation regarding disagreement: cooperation (winwin), competition (win-lose), struggle (win-lose), and warfare (lose-lose). The current study focuses on the first type - i.e., cooperation - since the participants were asked to carry out a collaborative task where disagreements were perceived as leading to a beneficiary situation for 39 all the group members; that is, a better analysis of their data and, therefore, a better final mark 40 in their assignments. 
different pragmatic expectations with regards to how to "disagree", will this lead to pragmatic failure and misunderstanding or will the participants follow commonly shared native-like "regulations"?

\section{Methodology}

\subsection{Setting}

The participants involved in this study were 10 masters students following a 10 course in English Linguistics, which meant their level of English was fairly advanced in general terms. Indeed, all the students in the group (except for two of them) were highly proficient in English (some of them being teachers of English as a foreign language in their countries of origin). The fact that they were not students of English as a second or foreign language was not seen as a problem. On the contrary, I firmly believed this could be turned into an advantage since it would make it possible, albeit in a limited way, to address the crucial question of the relationship between grammatical and pragmatic proficiency (Bardovi-Harlig 1999).

Besides the participants' high linguistic proficiency, there were three other crucial variables at play. To start with, the participants were well aware of their partners' language proficiency. Secondly, they had also developed a strong sense of community. This activity took place at the beginning of the spring term when students had already been together as a group for about six months. In fact, some of them had struck a close friendship outside the classroom. Finally, the task at hand demanded them to work closely together since students were warned the final mark would be equally shared by all the members in the group. This served to foster a highly collaborative environment, rather different from other ad-hoc scenarios in which English is used as a lingua franca among relative strangers (Kecskes 2007).

As for their gender and age, all the subjects enrolled in the course were female. Their age ranged from their mid-20s to their early 30s. They all came from a wide variety of countries so that English was the language used as a lingua franca both in the teacher-students and student-student interactions.

In order to avoid unnatural biased exchanges, the participants were not informed a priori of their participation in this research project but once the experiment was over. They were dutifully asked for their written consent, even if all the data were anonymous in order to protect their identities. In fact, and to maintain the subjects' anonymity, the learners are identified by a culturally and linguistically appropriate pseudonym (see Table 1). 
Table 1: Students' nationality and pseudonyms used in the study

\begin{tabular}{lll}
\hline & Students' nationality & $\mathbf{N}^{\circ}$ of students and pseudonym used \\
\cline { 2 - 2 } Bulgarian & Milena \\
5 & Egyptian & Anat \\
6 & Iranian & Anahit \\
7 South Korean & Chin \\
8 Polish & Kasia \\
9 Romanian & Adriana \\
Russian & Alina \\
\hline
\end{tabular}

\section{3.2 Procedure}

15

16 As already mentioned, the data used for the present study was collected at the 17 beginning of the spring term (the year is omitted for the sake of the participants' 18 anonymity). Students had to carry out a written assignment in groups. The 19 assignment consisted of analyzing a number of multimodal texts. To this pur20 pose, the participants were divided into three randomly made groups (group 1 21 included Anat, Adriana, and Anahit; group 2 consisted of Chin, Kasia, and Rocío; 22 finally, group 3 was formed by María, Isabel, and Alina; one of the students 23 Milena - enrolled when the course was already started, and she could not take 24 place in the assignment). Students had to carry out the analysis of the texts and 25 upload a final report with their results. However, they were required not to do this 26 collaborative analysis and writing in the traditional face-to-face way, but online, 27 more specifically, by means of the forum tool provided by the Moodle platform 28 the University offers. Thus, one forum was created for each of the three groups 29 and students had one week to do the activity. To avoid biasing students' interac30 tion, the teacher refrained from interfering except when explicitly asked for help.

\subsection{Data description}

35 The data used in the analysis consists of students' written contributions to the 36 three forums, where they negotiated their points of view regarding the task at 37 hand during the allotted week. In total, this sample comprises 15,598 words. 38 Despite its obvious limitations (both in size and in time span), the data at hand is 39 valuable as it provides us with an authentic sample of intercultural communica40 tion in ELF. 


\subsection{Rationale behind the data gathering process}

This section aims to explain the rationale behind this research and the reasons why this particular sample and methodology (and not others) have been chosen. The reasons why I opted for computer-mediated data (i.e., e-forums) instead of audio-recording students while they were undergoing the negotiation process were manifold:

i. I considered that students would be much more comfortable and, as a result, act more spontaneously if they were not being audio-recorded in the classroom but working in the safety of their own privacy. The presence of both the camera and the teacher could actually have biased their responses into less naturalistic ones.

ii. I intended to collect absolutely real data rather than use other methods such as DCTs or role plays. Hence, the forums were real tasks students had to engage with, and the language they were using was also totally natural and real. This is also why they ignored a priori that their interactions would be scrutinized.

iii. For practical reasons, it was much easier to gather computer-mediated data, which involved no time-consuming transcription apart from careful edition where the participants' real names were substituted by their pseudonyms (see table 1). Grammar or spelling mistakes made by the students were left untouched, without any correction or further edition.

\section{Data analysis}

As summed up by Angouri and Locher (2012: 1549), disagreement can be 28 approached from three different albeit related angles: content, form - i.e., lin- 29 guistic rendition - and the role it plays in interpersonal interaction. Differences in 30 content - i.e., what is being disagreed about - have not been considered in the present study since they are non-applicable. In other words, participants all express their agreement and disagreement on the same topic. Thus, I will focus mainly on the linguistic realization of the expressions of disagreement found in the corpus and on the relational work carried out by the participants. It is necessary to reiterate now that all the participants share a symmetrical relationship since all of them are classmates. The atmosphere in class is also remarkably relaxed and friendly, and all of them seem to get along remarkably well. In this context, disagreement is likely to be regarded as a welcome collaborative effort to reach a satisfactory consensus rather than as a conflicting, disrupting exchange. 
1 However, the participants' wish to keep on this friendly relationship among peers 2 makes disagreeing particularly challenging since they are still forced to "get one's 3 point across without seeming self-righteous or being injurious" (Locher 2004: 4 94).

\subsection{Toward a classification of "disagreement" expressions}

8

Disagreement expressions have been classified differently by different authors. It is beyond the scope of this article to review all of them in-depth. However, I will 1 briefly review here what I believe to be the four best-known and more commonly used taxonomies.

From a conversation analysis perspective, Pomerantz (1984) considers disagreement mostly as dispreferred, and she further differentiates strong from weak disagreement on sequential grounds. Hence, strong disagreements consist only of disagreement components (e.g., "I don't think so") whilst weak disagreements include other components like hesitation markers and fillers, token agreement components like "yes, but" and so on. Although encompassed within a different field, Pomerantz' classification is similar to the one put forward by Kakavá (1993), who also distinguishes between three linguistic realizations of disagreement: strong forms, strong yet mitigated, and mitigated forms of disagreement. The difference between the second and third types lies in the explicitness of disagreement in the second type, as opposed to the third type, in which disagreement may be accompanied by digression or reformulations. Valuable as these classifications are, they are based on face-to-face conversation and are not applicable to the present computer-mediated written data, in which there is no system of turns as such.

28 Rees-Miller (2000) bases her taxonomy on Brown and Levinson's (1987) 29 theory of politeness, paying particular attention to ranking and power differences. 30 Her classification also considers three types of disagreement. However, her "con31 tinuum" encompasses softened disagreement (either using positive or negative 32 politeness strategies), unmodified disagreement (equivalent to Pomerantz' strong 33 disagreement without any mitigation at all), and, finally, aggravated (intensified) 34 disagreement, which was not included in either Pomerantz's or Kakavá's classifi35 cations. This third type of disagreement - i.e., aggravated disagreement - is how36 ever typical of conflicting discourse and, as such, it has no place in the present study where, in fact, no conflict talk was identified.

38 Finally, a fourth taxonomy that has also been commonly used is the one put 39 forward by Kreutel (2007). One notable difference between this taxonomy and the 40 previous ones is that it was designed with learners of EFL and ESL in mind, rather 
than native speakers. Kreutel distinguishes between what she defines as "desir- 1 able features" and "undesirable features" in non-native speakers' expressions of 2 disagreement. In sum, she establishes the following taxonomy (2007: 326):

1. Desirable features:

a. Token agreement

b. Hedges

c. Requests for clarifications

d. Explanations

e. Expressions of regret

f. Positive remarks

g. Suggestions

2. Undesirable features:

a. Message abandonment

b. Total lack of mitigation

c. Use of the performative I disagree

d. Use of the performative negation I don't agree

e. Use of the bare exclamation no

f. Blunt statement of the opposite

In Kreutel's taxonomy, the degree of desirability depends on a comparison 20 with native speakers' expressions of disagreement. While it is true that this distinction between desirable and undesirable features is valuable, it is also somewhat naive since the expression of disagreement is always contextually bound and what could be desirable in a particular context might not be so in a different one. For example, a seemingly undesirable feature like a blunt disagreement might be the appropriate response in a conflictive context where the speaker indeed wants to make his/her point whilst it might be highly undesirable in a more collaborative context (like the one in the present study) where interlocutors are trying to maintain a good rapport. Indeed, recent studies have demonstrated that, in different contexts, native speakers also produce "undesirable disagreements" (e.g., Lawson 2009). This distinction, however, might be a consequence of the methodology employed to collect her data since Kreutel uses DCTs rather than naturally occurring exchanges.

Hence, for the present analysis, Kreutel's linguistic realizations have been renamed in accordance with Pomerantz's distinction between strong and weak or mitigated disagreement. The taxonomy applied in the following analysis is illustrated by Table 2 .

It goes without saying that speakers may opt for a combination of several 38 linguistic realizations in the same expression of disagreement, as in example (1), 39 where the speaker first requests for clarification ("Why do you think the prince is 40 
Table 2: Illocutionary force and linguistic realization of expressions of disagreement

\begin{tabular}{|c|c|}
\hline Strong disagreement & Mitigated disagreement \\
\hline \multicolumn{2}{|l|}{ Linguistic realizations } \\
\hline $\begin{array}{l}\text { Use of bare negative forms (e.g., } \\
\text { "no," "no way," "of course not") }\end{array}$ & Token agreement (e.g., “yeah ... but”) \\
\hline Use of the performative "I disagree" & $\begin{array}{l}\text { Use of hedges (e.g., “I guess,” “it seems,” “I don’t } \\
\text { really know," etc.) }\end{array}$ \\
\hline $\begin{array}{l}\text { Use of the performative negation “I } \\
\text { don't agree” or “I can't agree” }\end{array}$ & $\begin{array}{l}\text { Requests for clarification (e.g., “maybe I didn’t } \\
\text { understand, could you explain it more clearly?”) }\end{array}$ \\
\hline Blunt statement of the opposite & $\begin{array}{l}\text { Expressions of regret (e.g., “I’m sorry but I don’t } \\
\text { agree with you ...”" }\end{array}$ \\
\hline $\begin{array}{l}\text { Use of insults and negative } \\
\text { judgments (e.g., "you are a moron”) }\end{array}$ & $\begin{array}{l}\text { Use of prefacing positive remarks towards the } \\
\text { addressee (e.g., "that's a very good analysis") } \\
\text { Suggestions (e.g., "How about doing it in a slightly } \\
\text { different way?") } \\
\text { Giving explanations }\end{array}$ \\
\hline
\end{tabular}

16

depicted in this way?") and then uses hedges to make her own point ("I'm not sure about this, but I think"):

\section{Example 1}

Why do you think the prince is depicted in this way?... I'm not sure about this, but I think the fact that the prince is depicted with his whole body in the first image might enhance his strenght [sic] .. and therefore power over Snow White

\section{4.2 Data analysis}

30 For methodological clarity, the different linguistic realizations summed up in 31 Table 2 are analyzed in the two following subsections. Given the complexity of 32 this speech act, I have opted mostly for a more qualitative approach rather than a 33 purely quantitative analysis.

\section{4.2.1 Strong disagreement}

38 Strong disagreement is characterized by the lack of mitigation of any sort. In

39 other words, the head act consists of bare negative forms (e.g., "no way," "no, 40 no, no," "of course not," etc.), the use of performative verbs ("I disagree”) or 
the blunt statement of the opposite. For Kreutel (2007), strong disagreement 1 is undesirable and is more frequently employed by nonnative speakers than 2 by their native counterparts. As already stated, this might be a result of her 3 methodology.

In the current sample, participants seem to be aware that the use of bare negative forms can be too face-threatening in a cooperative context with their peers. As a result, not a single example of such expression of disagreement can be found. The same happens with regards to the use of the performative verbs ("I 8 disagree") or expressions such as "I don’t agree." There is not a single example in the sample under investigation where the performative "I disagree" is used. With regard to the negative performative "I don't agree," it only appears on three occasions, as illustrated by examples (2), (3), and (4). In all of them, however, it is also carefully mitigated:

\title{
Example 2
}

Excellent analysis, Anat! $\Theta$. There's just one point I don't agree with: the fact that the two characters have the same role in the 1985 image.. It's true that both the prince and Cinderella are Reacters and Phenomena (I think we can say this is a 'reciprocal mental process' or 'bidirectional transactional reaction' ...). However, whereas the prince only turns his head towards Cinderella, she turns her whole body towards him, so this is why I don't think their roles are equal.

In example (2), the disagreement starts with a positive comment on Anat's previous work ("Excellent analysis, Anat! 9 ") before moving on to the disagreement proper or head act. In this case, it is also mitigated by the use of "just one point" and hedges like "I think" together with deep reasoning why she disagrees with her classmate, finalized by the use of another hedge "this is why I don't think their roles are equal." The use of the emoticon is also worth pointing out, since it helps to add a friendly tone to the debate and boosts group solidarity.

Example (3) also makes use of the negative performative ("I still do not completely agree"). In this case, the mitigation is carried out by minimizing the disagreement ("there is one part"), giving reasons and explanations why she disagrees, using hedges ("I think ...," "it seems") and, finally, asking for the other member's opinion (“what do you think Rocío?”)

\section{Example 3}

There is one part in the text on which I still do not completely agree with Chin. The picture of the prince and Cinderella kissing, I think Cinderella is an actor in this case because it seems like she is kissing the prince back; however, Chin sees her as a passive participant; what do you think Rocio?

\section{6} -12
17

\section{8} 19 20

\section{4} 25 26

\section{7} 28

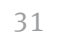




\section{Example 4}

In this sentence, there are two participants and both of them are the actors, because they have an active participation. They are the agents of 'married' and 'lived.'

I'm sorry but I don't agree with Chin's comment: "The text includes both actor and goal as shown in 'they.'

For me, there isn't any goal.

I have found the following example in a novel by Hemingway:

'He was married by the first lady who was nice to him'

In this sentence, 'he' is the goal because it is a passive sentence and the agent is 'by

10 the first lady who was nice to him.' The verb 'married' is a material process of doing

11 as in our example.

12 I just want to help you to understand it, Chin, but my explation [sic] may not be so 13 good.

14

15 Example (4) is particularly attractive since the speaker starts by bluntly stating

16 the opposite ("in this sentence, there are two participants and both of them are 17 actors ..."). She tries to mitigate her disagreement by using the apologetic "I'm

18 sorry." After repeating her point ("for me, there isn't any goal”), she proceeds to

19 make a longish explanation that justifies her position. The entire text is closed by

20 appealing to modesty ("my explanation may not be so good"). Quite remarkably,

21 the speaker here has a high linguistic competence in English (as she has also

22 demonstrated in class) but it could be said that her pragmatic competence is

23 slightly faulty since her mitigating devices come rather late. As a result, the

24 beginning of her message sounds particularly harsh. It is obvious, however, that

25 she is trying to be friendly and to work on group rapport rather than being "con-

26 flictive." What seems to be lacking is what Kreutel (2007: 338) has defined as "the

27 sandwich pattern," where mitigation happens both before and after the actual

28 disagreement rather than just after it.

29 Despite being nonnative speakers, the participants in this study carefully

30 avoid strong disagreement. This might be a result of their high linguistic compe-

31 tence (although there are some obvious linguistic "mistakes" such as the occa-

32 sional use of "I am agree" or blunt disagreements like the one above, which might

33 sound harsh and somewhat rude). As stated by Bardovi-Harlig (1999), a high lin-

34 guistic competence might help with pragmatic competence but does not guaran-

35 tee it. The current data contradict previous research (e.g., Pearson 1986; Beebe

36 and Takahashi 1989) and aligns with more current studies, which have also re-

37 flected that non-native speakers do not use these alleged "undesirable features"

38 (Kreutel 2007) as much as it was originally thought.

39 In addition, the absence of strong disagreements might also be related to a

40 common desire to keep the area free of conflict since the participants know they 
are involved in a collaborative task. In such a situation, proving too conflictive might have a negative effect in the future development of their relationship. Thus, 2 we observe what Wolfson (1990) defines as “the bulge effect.” In Kreutel's (2007: 333) interpretation, "Wolfson attributes this phenomenon to the fact that relationships between status-equals have the potential for a reduction of the existing social distance since the status of the relationship is relatively uncertain and therefore open to redefinition."

\subsubsection{Mitigated disagreement}

As opposed to strong disagreement, mitigated disagreement is characterized by the use of linguistic elements that help minimize the face-threat of a direct, blunt disagreeing statement. Among these linguistic strategies, the most common and so-called "desirable" features are as follows: token agreement (i.e., the "yes, but" formula), the use of hedges, requests for clarification, expressions of regret, use of positive remarks, suggestions, and giving explanations.

\subsubsection{Token agreement}

The use of token agreement as the most frequent strategy employed by native speakers has been corroborated by several authors (Pomerantz 1984; LoCastro 1986; Pearson 1986; Kothoff 1993; Kuo 1994; Burdine 2001; Locher 2004; among others). Despite being nonnative speakers of English, the current participants employ token agreement on 14 occasions, both as the only mitigating strategy as in example (5) - and, more frequently, as part of a more complex, combined answer (see Examples (6), (7), and (8)).

Example 5

Isabel, I totally agree with your first analysis fairy tales have not changed much in twenty years, as regards images in both Cinderella and Snow White. However, I 32 would like to point something that strikes me in the images of Snow White in 2005 if you have a look at both the princes and the princess they are more or less at the same level, I mean in the picture. In the images of Cinderella in 2005 the princess is like in a superior position from the prince in a step, although she is the goal.

\section{Example 6}

I agree with the last part. But, why do you think Cinderella is a phenomenon in 2005? I think the prince is not smiling at her since she's looking out of the window.

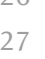

\section{西}


1 In example (6), token agreement ("I agree ... but") is used in combination with other mitigating strategies - asking for the interlocutor's opinion ("why do you 3 think ...?"), hedges ("I think ...”) and explanations ("since she's ...”). Examples (7) and (8) are even more elaborated:

\section{Example 7}

I agree with your analysis of her hand gesture:D In fact she seems to be leaned a lil bit backwards which adds to her surprise. The only explanation I can think of is that she considers herself inferior to him and she is surprised that the prince is inviting her to dance. Hence, I agree that she believes she is unworthy of his attention and feels she doesnt [sic] deserve it, but I think it's because of his social status. Still, it could also be because he chose her. As if men are the ones to choose and you're lucky if he chose you.

In this case, the speaker starts with a token agreement (already mitigated by means of the emoticon) and rephrases the interlocutor's interpretation before actually disagreeing with it ("but I think ..."). This is further mitigated by means of hedges ("The only explanation I can think of," "I think," "still, it could also be").

\section{Example 8}

23 Very interesting analysis, Anat! Thank you for posting it! $: ;$

24 My ideas concerning Task 3 are basically the same, except for the third pair of 25 images. I think the 1985 image rather than complementary/enhancing is contradic26 tory... I don't see any sign of the Prince and Snow White being happy in that image; 27 it's rather a gloomy image in my opinion. I agree with your reading of the Palace as 28 a symbol of wealthiness and power.

30 Example (8) also presents a combined answer where the token agreement ("My 31 ideas are basically the same, except for ...”) is preceded by another mitigating 32 strategy - i.e., positive evaluation of the interlocutor and acknowledgement of 33 her work ("very interesting analysis, Anat! Thank you for posting it! (-)"). The 34 interlocutor obviously wants to disagree in an extremely mitigated way, avoiding 35 the disruption of the good rapport the group has already built. This is why she 36 starts her actual disagreement with a hedge ("I think") and finally closes her 37 comments by agreeing on a related aspect. This pattern [token agreement + 38 disagreement + agreement] reflects what Kreutel (2007: 338) defines as "sandwich 39 pattern": "Most of the NSs [native speakers] use mitigation not only at the begin40 ning of their utterances, but also at the end, creating a certain sandwich pattern 
that "wraps" the dispreferred speech act into preferred reactions" [emphasis in 1 the original].

Quite remarkably, examples like (7) and (8) are produced by two of the participants with an extremely high linguistic proficiency (Anat and Adriana, respectively), which may give us an indication that linguistic proficiency certainly helps in developing pragmatic competence. Interestingly enough, none of the weakest students in the class (Anahit and Rocío) produce any token agreement or combined responses. In the case of Anahit, she opts for what could be considered as message abandonment (a highly undesirable feature according to Kreutel) since she does not provide any answers to the questions made by her group members. Rocío (whose linguistic proficiency is slightly higher than Anahit's but lower than her other classmates') always mitigates her disagreement by means of hedges and expressions of regret. The latter might be a clear transfer from her L1 (Spanish), as example (9) shows:

Example 9

I am so sorry but I don't see any Cinderella kissing the prince, do you mean Snow White? In this case, I think that the prince is the actor. She is not an actor because he is kissing her but not the other way around.

do you mean that??? 2 3 4 6 8 9 10 11 12

\subsubsection{Use of hedges}

Defined by Lakoff (1972: 195) as words "whose jobs it is to make things more or 24 less fuzzy," hedges are also considered as mitigating strategies. In his study on 25 disagreement, Lawson (2009: 25) presents the list of hedges employed by his par- 26 ticipants (Japanese and American speakers). His list can be further classified into 2 four main types, as illustrated by Table 3.

Table 3: Hedges employed in disagreement (adapted from Lawson 2009: 25)

\begin{tabular}{ll}
\hline Type of hedge & Examples \\
\hline Initial / mid-speech pauses* & Uhm, eh \\
Subject + verb minor clauses & $\begin{array}{l}\text { I think, I don't think, I guess, I'm (not) sure, it appears, } \\
\text { it seems, etc. } \\
\text { Modal hedges (adverbs, verbs) }\end{array}$ \\
Maybe, probably, possibly. Modal verbs. \\
Others & Somewhat, kind of, a bit, etc. \\
\hline
\end{tabular}

* Given the written nature of the corpus analysed in this paper, this type of hedges do not occur since they are typical of oral discourse. 

2 by the participants, which replicates other studies such as Lawson's (2009) and 3 Kreutel (2007) where nonnative speakers also use hedges profusely. Favorite 4 hedges seem to be "I think," modal verbs (especially "could" and "may") and 5 modal adverbs like "maybe." Usually, hedges are used in combination with other 6 strategies as illustrated by examples (10) to (12) below:

\section{Example 10}

9 So, I don't think it's radical :D:D I think we should include your interpretation:D 10

11 Example (10) forms part of a longer exchange in which one of the members in the 12 group (Adriana) has suggested what she considers might be a radical interpreta13 tion. Anat's disagreement is apparently too direct. However, in this particular 14 context it might be desirable to disagree so as to encourage Adriana's analysis. 15 Approbation is also enhanced by the use of the double emoticon and the final 16 hedged decision to include her analysis. From the point of view of relational work, 17 this excerpt shows how the participants are carefully defining their relationship 18 as group members; their use of positive politeness strategies (e.g., praising the 19 other, using the inclusive pronoun "we") and emoticons help build their relation20 ship as symmetrical and friendly, where all opinions are worth listening to.

21

22 Example 11

23 It seems that we have a similar analysis more or less. However, I'm not sure whether 24 they are represented as equals. I think that even though the gap between them is 25 reduced in the second image, we still have the prince as the active actor. So, they 26 don't have an equal representation.

27 What do you think?

28

\section{Example 12}

30 Why do you think the prince is depicted in this way?' . I'm not sure about this, but 31 I think the fact that the prince is depicted with his whole body in the first image 32 might enhance his strength [sic] .. and therefore power over Snow White..the face, 33 on the contrary, is not clearly shown, since it is the part of our body that shows our 34 emotions ... so maybe in 1985 the prince's feelings towards Snow White were not 35 considered so important. In the 2005 image, we can see the prince's face, his eyes 36 closed while kissing Snow White, which might indicate a deep feeling of love towards 37 her.

38 Please let me know what you think about these issues and then maybe we could go

39 on with the other images. :-

40 Adriana 
Examples (11) and (12) illustrate how hedges are usually combined with other 1 mitigating strategies like asking for the other's opinion, requesting for clarifica- 2 tions and giving explanations. Hedges are also employed by the weakest students, 3 as examples (13) and (14) show, where Rocío states the following:

\section{Example 13}

Hi girls, I am sorry to answer so late but, as you know Chin, I am still sick.

Well, I think that when Chin says there are two participants, she refers to the actor and the goal, but I am not sure if we have to consider Snow White as a participant because she is passive.

\section{Example 14}

And in this sentence: 'he' is the Sayer and 'asked' is a verbal process and what follows is a verbiage. I don't think that it is a verbiage because the sentence is 'he asked her' and verbiage: it is what you say, and in this case we have a person. I think it is called a receiver.

We should change this too. ???

As can be observed, the weakest students seem to favor the use of hedges like "I (don't) think" or "I am not sure" rather than other hedges like modal verbs, whose usage is bound to be more complicated for them. This may be due to the fact that expressions like "I think" and "I don't think so" are introduced in the early stages of the learning process whilst modal verbs tend to appear later. In contrast, those students with a high linguistic competence seem fairly comfortable with the use of hedges.

\subsubsection{Giving explanations}

Accompanying disagreement acts by an explanation minimizes its face- 28 threatening nature, as also happens with other speech acts like refusals (e.g., Al 29 Khatib 2006). Giving reasons for acting against the addressee's convenience thus 30 minimizes face-threat. In the sample under study, giving explanations is used on 31 14 occasions, as illustrated by examples (15) and (16) below:

Example 15

I agree with your analysis of invited her to dance. I thought it was material because you could invite someone without the need of speech. His gesture would be an indication of this. However, I think we could consider it verbal.

Example 16

Very interesting analysis, Anat! Thank you for posting it! (;) 
1 My ideas concerning Task 3 are basically the same, except for the third pair of im2 ages. I think the 1985 image rather than complementary/enhancing is contradictory 3 ... I don't see any sign of the Prince and Snow White being happy in that image; it's rather a gloomy image in my opinion. I agree with your reading of the Palace as a symbol of wealthiness and power.

6 Regarding your 'General Comments', I think the professor said in class that comple7 mentary and enhancing usually go together, so maybe it's not necessary to make 8 any changes.

9

10 In (15), we can observe a clear example of Kreutel's "sandwich pattern." The 11 explanation is given just after the initial agreement ("I thought it was material 12 because...”). As for (16), it presents a more elaborate combination of strategies, 13 starting with a positive remark ("very interesting ..."), followed by token agree14 ment ("my ideas are basically the same, except for ..."). The explanation seems 15 to be split; the speaker first states her opinion ("I don't see any sign [...] in my 16 opinion") but then supports her initial explanation with the authoritative voice of 17 the teacher ("I think the professor said in class ..."). As can also be observed, all 18 of it is carefully hedged ("I think," "I don’t see," “maybe”). Significantly, giving 19 explanations is a strategy used more frequently by those students with a high 20 level of linguistic proficiency. The student with an intermediate level (Rocío) 21 employs explanations just on two occasions, as illustrated by example (17):

22

\section{Example 17}

24 In my opinion, she doesn't kiss the prince because this is not possible. She is sleep25 ing. But if you two think in other way, we can put that. But I don't think she is an 26 actor because she does nothing, because she is sleeping.

27

28 Here, she repeats her explanation twice, which proves that it is a determinant 29 point for her in how to analyze the text ("because this is not possible. She is sleep30 ing” and "because she is sleeping”). Although she uses hedges ("I don't think") 31 and tries to please her classmate ("But if you think in other way, we can put 32 that"), she ends up her comment by again stating her disagreement. It could be 33 argued that, even if she is using mitigating strategies, the whole tone of her mes34 sage is quite harsh. This is probably due to the fact that she still does not control 35 the "sandwich pattern" structure.

36

37

\section{4.2.2.4 Requesting for clarifications}

39 Requesting for clarifications can be considered as a mitigating device insofar as it

40 gives the addressee the possibility of explaining and clarifying her point again so 
as to avoid possible disagreement. In the sample, requests for clarification appear 1 on nine occasions, either in isolation (example [18]) or usually in combination 2 with other strategies (examples [19] and [20]).

\section{Example 18}

inside the verbiage (1985), where there is a mental process, the Phenomenon (which I think is "to dance") is missing; did you forget to mention it, or you don't consider it to be the Phenomenon?

\section{Example 19}

I agree with the last part. But, why do you think Cinderella is a phenomenon in 2005? I think the prince is not smiling at her since she's looking out of the window.

In (19), a token agreement is combined with a request for the addressee's opinion and clarification on her previous analysis ("why do you think ..."). The speaker's disagreement is hedged ("I think") and further explained ("since ...").

\section{Example 20}

Girls, I think we still need to work on the second part. There are some things which are not clear to me. Chin mentions that there is the goal and then she says that there is no goal. Chin could you clarify a bit? Maybe we should talk about it in here and then copy the final version to our file. We can leave it for tomorrow also, I have another assignment to work on so I think I will leave this one for today.

Thanks,

Kasia

In example (20), Kasia precedes her disagreement ("there are some things which are not clear to me") by a direct appeal to group solidarity ("girls") and a hedged statement ("I think we still need ..."). This is further followed by a direct address to one of the group's members, who is requested to clarify her contradictory analysis (“Chin could you clarify a bit?"). Finally, a hedged suggestion appealing again to group solidarity ("Maybe we should talk ...") and a token of appreciation ("thanks") closes the disagreement move.

Quite significantly, closer inspection of the data reveals that this strategy is exclusively used by three participants (Adriana, Anat, and Kasia), who are also those with the highest level of linguistic proficiency. These three participants reported they had lived in the UK and are themselves rather multicultural since they have also lived in Spain for a long while. This exposition to different cultural backgrounds seems to have been extremely beneficial in their understanding of 
1 pragmatic differences that, together with their linguistic proficiency, account for their use of a wider range of strategies when expressing disagreement.

3

4

\section{5}

6

\title{
4.2.2.5 Expressions of regret
}

According to Kreutel (2007), expressions of regret are often overused by nonnative speakers. This might be due to the fact that the acquisition of the expression "I'm sorry" occurs at the earliest stages of L2 learning. As pointed out by Kreutel, the overuse of this strategy by non-native speakers might have unwelcome effects:

\begin{abstract}
I'm sorry is said to be generally overused by non-native speakers because it is acquired relatively early and used as a general means of avoiding confrontation by expressing humbleness and deference. Conversely, among native speakers, I'm sorry is usually associated with apologies, that is, the speaker acknowledges a mistake or failure on his or her part. [...] This expression of reverence may be inappropriate when it comes to disagreement, indicating that a differing opinion is not necessarily a failure the speaker needs to apologize for. Accordingly, ESL learners should be sensitized that this feature reduces the authority and power behind a statement and may lead to the disagreement not being taken seriously by the listener. (Kreutel 2007: 331)
\end{abstract}

Contrary to expectations, expressions of regret only occur twice in the sample. Quite remarkably, however, they are both produced by Rocío (one of the speakers with a lower linguistic proficiency), as illustrated by example (21) (see also example [4]):

\section{Example 21}

I am so sorry but I don't see any Cinderella kissing the prince, do you mean Snow White? In this case, I think that the prince is the actor. She is not an actor because he is kissing her but not the other way around.

\subsubsection{Positive remarks}

The last mitigating strategy consists of producing an appraising comment toward the addressee so as to minimize the negative effect on her positive face caused by the upcoming disagreement. Directly related to Leech's (1983) maxim of approbation - i.e., maximize praise of the hearer - this strategy is used on four occasions and in all cases, it is employed by two of the students with a high linguistic proficiency (Adriana and Kasia) (see examples (2), and [8]). An extract of a longer exchange by Kasia (example [22]) also illustrates this strategy: 
Example 22

Hello girls,

Great work Chin. I am very impressed $\ddot{\theta}$

Here are my suggestions.

\section{Conclusions}

The present paper intended to answer the following research question, repeated 10 here for the sake of clarity: In a multicultural class where English is the medium 1 of instruction and students' peer-to-peer communication, whose pragmatic "rules" are followed? In other words, do nonnative speakers using English as a 13 lingua franca follow their own pragmatic rules or those of native speakers (i.e., 14 American, British, New Zealand English, or any of the multiple varieties of the 15 target language)?

Results show that the participants with a high linguistic proficiency closely follow the same strategies native speakers do in order to avoid face-threat (not only toward their interlocutors' face but also to their own). Moreover, they display a wide range of native-like strategies such as requesting for clarification, produc- 20 ing positive remarks or giving explanations. It follows from this that linguistic 2 proficiency - at least in the case of the participants in the current experiment - 22 clearly plays a vital role in the development of pragmatic competence. In the case 23 of these participants, their heightened intercultural awareness was also boosted 24 by their own personal experience since most of them had lived in the UK for a 25 while and then in Spain, which was not their home country either. This contact 26 with different cultures - and their respective languages - seems to have had a 27 highly beneficial effect on their intercultural pragmatics.

Together with linguistic proficiency, there seem to have been other crucial variables at play, namely: the familiarity with the other participants' linguistic proficiency, the fact that they had known one another for about six months and were far from being complete strangers, and the highly collaborative nature of the task at hand. This scenario proves rather different from ad-hoc situations in which interactants meet only for a short time and have a leisurely conversation about topics like food, travel, or else. Hence, it comes as no surprise that this particular context leads to different results in contrast with previous research (see Kecskes 2007).

In this particular case, students were not afraid of sticking to the original 38 rules of the game and followed the common rules of the native variety they all 39 shared: Standard British English. This allowed them to discuss and negotiate 40 
more comfortably according to common rules that avoided pragmatic failure and facilitated a satisfactory fulfillment of their group task.

With regards to the two participants whose linguistic proficiency was markedly lower, one of them is observed trying to play by the rules, albeit in a more limited way. In fact, she employs hedges and other strategies such as the use of apologetic comments. The other, unfortunately, follows the common strategy of simply abandoning the message, most likely as a result of her lack of linguistic abilities. Indeed, the ongoing stage in this research project is to address the issue of whether these participants with lower linguistic proficiency competence can be taught the necessary pragmalinguistic tools to make them pragmatically more 1 competent in intercultural situations like the one described here. Future research 2 also intends to work on a larger corpus from a quantitative approach.

\section{References}

16

Al Khatib, Mahmoud A. 2006. The pragmatics of invitation making and acceptance in Jordanian society. Journal of Language and Linguistics 5. 272-294.

Angouri, Jo and Miriam A. Locher. 2012. Theorising disagreement. Journal of Pragmatics 44(12). 1549-1553.

Angouri, Jo and Meredith Marra. 2012. "OK one last thing for today then”: Constructing identities in corporate meeting talk. In Jo Angouri and Meredith Marra (eds.), Constructing identities at work, 85-100. Hampshire: Palmgrave Macmillan.

Bardovi-Harlig, Kathleen. 1999. Exploring the interlanguage of interlanguage pragmatics: A research agenda for acquisitional pragmatics. Language learning 49(4). 677-713.

Bardovi-Harlig, Kathleen and Tom Salsbury. 2004. The organization of turns in the disagreements of L2 learners: A longitudinal perspective. In Diana Boxer and Andrew D. Cohen (eds.), Studying speaking to inform second language learning, 199-227. Clevedon: Multilingual Matters.

Baym, Nancy. 1996. Agreements and disagreements in a computer-mediated discussion. Research on language and social interaction 29(4). 315-345.

Beebe, Leslie M. and Tomoko Takahashi. 1989. Sociolinguistic variation in face-threatening speech acts. Chastisement and disagreement. In Miriam R. Eisenstein (ed.), The dynamic interlanguage: Empirical studies in school language variation, 199-218. New York: Plenum.

Bell, Nancy. 1998. Politeness in the speech of Korean ESL learners. Working papers in educational linguistics 14(1). 25-47.

Bolander, Brook. 2012. Disagreements and agreements in personal/diary blogs: A closer look at responsiveness. Journal of Pragmatics 44(12). 1607-1622.

Bond, Michael Harris, Vladimir Zegarac, and Helen Spencer-Oatey. 2000. Culture as an explanatory variable: Problems and possibilities. In Helen Spencer-Oatey (ed.), Culturally speaking: Managing rapport through talk across cultures, 293-315. London: Continuum.

Brown, Penelope and Stephen C. Levinson. 1987. Politeness: Some universals in language use. Cambridge: Cambridge University Press. 
Burdine, Stephanie. 2001. The lexical phrase as pedagogical tool: Teaching disagreement strategies in ESL. In Rita C. Simpson and John M. Swales (eds.), Corpus linguistics in North America: Selections from the 1999 Symposium, 195-210. Ann Arbor: University of Michigan Press.

Díaz Pérez, Francisco Javier. 2003. La cortesía verbal en inglés y en español: Actos de habla y pragmática intercultural. Jaén: Universidad de Jaén.

García, Carmen. 1989. Disagreeing and requesting by Americans and Venezuelans. Linguistics and Education 1. 299-322.

Georgakopoulou, Alexandra. 2001. Arguing about the future: On indirect disagreements in conversations. Journal of Pragmatics 33(12). 1881-1900.

Grimshaw, Allen D. 1990. Conflict talk: Sociolinguistic investigations in conversations. Cambridge: Cambridge University Press.

Gruber, Helmut. 2001. Questions and strategic orientation in verbal conflict sequences. Journal of Pragmatics 33. 1815-1857.

Hayashi, Takuo. 1996. Politeness in conflict management: A conversation analysis of dispreferred message from a cognitive perspective. Journal of Pragmatics 25(2). 227-255.

Holmes, Janet and Meredith Marra. 2004. Relational practice in the workplace: Women's talk or gendered discourse? Language in Society 33(3). 377-398.

House, Juliane. 2002. Communicating in English as a lingua franca. Eurosla Yearbook 2(1). 243-261.

House, Juliane. 2003. English as a lingua franca: A threat to multilingualism? Journal of Sociolinguistics 7. 556-578.

Hülmbauer, Cornelia, Heike Böhringer, and Barbara Seidlhofer. 2008. Introducing English as a lingua franca (ELF): Precursor and partner in intercultural communication. Synergies Europe 3. 25-36.

Kakavá, Christina. 1993. Negotiation of disagreement by Greeks in conversations and classroom discourse. Washington, DC: Georgetown University PhD dissertation.

Kakavá, Christina. 2002. Opposition in Modern Greek discourse: cultural and contextual constraints. Journal of Pragmatics 34. 1537-1568.

Kecskes, Istvan. 2007. Formulaic language in English Lingua Franca. In Istvan Kecskes and Lawrence R. Horn (eds.), Explorations in pragmatics: Linguistic, cognitive and intercultural aspects, 191-213. Berlin: Mouton de Gruyter.

Kempf, Wilhelm. 2003. Constructive conflict coverage: A social psychological approach. Berlin: Irena Regener.

Knapp, Karlfried and Christiane Meierkord (eds.). 2002. Lingua franca communication. Frankfurt: Peter Lang.

Kotthoff, Helga. 1993. Disagreement and concession in disputes: on the context sensitivity of preference structures. Language in Society 22.193-216.

Koutsantoni, Dimitra. 2005. Greek cultural characteristics and academic writing. Journal of Modern Greek Studies 23. 97-138.

Kreutel, Karen. 2007. “I'm not agree with you.” ESL learners' expressions of disagreement. TESL-EJ 11(3). 1-35.

Kuo, Sai-hua. 1994. Agreement and disagreement strategies in a radio conversation. Research on language and social interaction 27(2). 95-121.

Lakoff, George. 1972. Hedges: A study in meaning criteria and the logic of fuzzy concepts. Chicago Linguistic Society papers 8. 183-228. 
1 Langlotz, Andreas and Miriam A. Locher. 2012. Ways of communicating emotional stance in online disagreements. Journal of Pragmatics 44(12). 1591-1606.

Lawson, Andrew J. 2009. From the classroom to the bar-room: Expressions of disagreement by Japanese speakers of English. Master dissertation, University of Birmingham.

Leech, Geoffrey N. 1983. Principles of pragmatics. New York: Longman.

Liang, Guodong and Jing Han. 2005. A constrative study on disagreement strategies for

6 politeness between American English and Mandarin Chinese. Asian EFL Journal 7(1).

$7 \quad 1-12$.

8 LoCastro, Virginia. 1986. "Yes, I agree with you. But ...": Agreement and disagreement in Japanese and American English. Paper presented at the Japan Association of Language Teachers' International Conference on Language teaching and learning, University of Japan, 22-24 November.

Locher, Miriam A. 2004. Power and politeness in action: Disagreements in oral communication. Berlin: Mouton de Gruyter.

3 Marra, Meredith. 2012. Disagreeing without being disagreeable: Negotiating workplace communities as an outsider. Journal of Pragmatics 44(12). 1580-1590.

Meierkord, Christiane. 2000. Interpreting successful lingua franca interaction: An analysis of non-native/non-native small talk conversations in English. Linguistik online 5(1). Accessed 3 July 2013 <http://www.linguistik-online.com/1_00/index.html>.

7 Muntigl, Peter and William Turnbull. 1998. Conversational structure and facework in arguing. 18 Journal of Pragmatics 29(3). 225-256.

19 Nakajima, Yuko. 1997. Politeness strategies in the workplace: Which experiences help Japanese businessmen acquire American English Native-like strategies? Working Papers in Educational Linguistics 13(1). 49-69.

Pearson, Eloise. 1986. Agreement/disagreement: An example of results of discourse analysis applied to the oral English classroom. ITL Review of Applied Linguistics 74. 47-61.

23 Pomerantz, Anita. 1984. Agreeing and disagreeing with assessments: Some features of preferred/dispreferred turn shapes. In Atkinson, J. Maxwell and John Heritage (eds.), Structures of social action: Studies in Conversation analysis, 57-103. Cambridge: Cambridge University Press.

Rees-Miller, Janie. 2000. Power, severity, and context in disagreement. Journal of Pragmatics 32(8). 1087-1111.

Santamaría-García, Carmen. 2006. La negociación de acuerdo en la conversación coloquial: Estudio contrastivo español-inglés. Madrid: Universidad Complutense de Madrid PhD dissertation.

Schiffrin, Deborah. 1984. Jewish argument as sociability. Language in Society 13. 311-335.

Seidlhofer, Barbara. 2004. 10 Research perspectives on teaching English as a lingua franca. Annual Review of Applied Linguistics 24(1). 209-239.

Seidlhofer, Barbara. 2005. English as a lingua franca. ELT Journal 59(4). 339.

Sifianou, Maria. 1992. Politeness phenomena in England and Greece: A cross-cultural perspective. Oxford: Clarendon Press.

Sifianou, Maria. 2012. Disagreements, face and politeness. Journal of Pragmatics 44. 15541564.

Tannen, Deborah. 1994. The relativity of linguistic strategies: rethinking power and solidarity in gender and dominance. In Deborah Tannen (ed.), Gender and discourse, 19-52.

39 Oxford: Oxford University Press.

40 Tannen, Deborah. 2002. Agonism in academic discourse. Journal of Pragmatics 34. 1651-1669. 
Tannen, Deborah and Christina Kakavá. 1992. Power and solidarity in Modern Greek conversation: Disagreeing to agree. Journal of Modern Greek Studies 10(1). 11-34.

Wolfson, Nessa. 1990. The bulge: A theory of speech behavior and social distance. Penn working papers in educational linguistics 2(1). 55-83.

\section{Bionote}

Carmen Maíz-Arévalo obtained her PhD in English Linguistics in 2001. Currently Dr. Maíz-Arévalo holds the position of full time lecturer at the Universidad Com- 10 plutense, where she teaches Pragmatics, English and Intercultural studies. She 11 has published numerous articles on these issues and taken part in many national 12 and international conferences. Dr. Maíz-Arévalo is also the secretary of the Revista 13 de Estudios Ingleses de la Universidad Complutense. 14 